\title{
Prediction of present and future distribution of the Schlegel's Japanese gecko (Gekko japonicus) using MaxEnt modeling
}

Dae-In Kim ${ }^{1 \dagger}$, II-Kook Park ${ }^{1 \dagger}$, So-Yeon Bae ${ }^{2}$, Jonathan J. Fong ${ }^{3}$, Yong-Pu Zhang ${ }^{4}$, Shu-Ran Li ${ }^{4}$, Hidetoshi Ota ${ }^{5}$, Jong-Sun Kim ${ }^{6}$ and Daesik Park ${ }^{6 *}$ (D)

\begin{abstract}
Background: Understanding the geographical distribution of a species is a key component of studying its ecology, evolution, and conservation. Although Schlegel's Japanese gecko (Gekko japonicus) is widely distributed in Northeast Asia, its distribution has not been studied in detail. We predicted the present and future distribution of $G$. japonicus across China, Japan, and Korea based on 19 climatic and 5 environmental variables using the maximum entropy (MaxEnt) species distribution model.

Results: Present time major suitable habitats for G. japonicus, having greater than 0.55 probability of presence (threshold based on the average predicted probability of the presence records), are located at coastal and inland cities of China; western, southern, and northern coasts of Kyushu and Honshu in Japan; and southern coastal cities of Korea. Japan contained $69.3 \%$ of the suitable habitats, followed by China (27.1\%) and Korea (4.2\%). Temperature seasonality (66.5\% of permutation importance) was the most important predictor of the distribution. Future distributions according to two climate change scenarios predicted that by 2070 , and overall suitable habitats would decrease compared to the present habitats by $18.4 \%$ (scenario RCP 4.5) and 10.4\% (scenario RCP 8.5). In contrast to these overall trends, range expansions are expected in inland areas of China and southern parts of Korea.

Conclusions: Suitable habitats predicted for G. japonicus are currently located in coastal cities of Japan, China, and Korea, as well as in isolated patches of inland China. Due to climate change, suitable habitats are expected to shrink along coastlines, particularly at the coastal-edge of climate change zones. Overall, our results provide essential distribution range information for future ecological studies of $G$. japonicus across its distribution range.
\end{abstract}

Keywords: Lizard, Distribution range, Climate change, Temperature seasonality, Urban

\section{Background}

Data on the geographical distribution are basic information needed for studying the ecology, evolution, and conservation of a species (Franklin 2009). In recent years, determining the explicit distribution range of a species and predicting future changes has become more important because of rapid population declines due to habitat destruction and alteration, climate change, and introduced

\footnotetext{
* Correspondence: parkda@kangwon.ac.kr

Dae-In Kim and II-Kook Park are Co-first authors.

${ }^{6}$ Division of Science Education, Kangwon National University,

ChuncheonKangwon, 24341, Republic of Korea

Full list of author information is available at the end of the article
}

species (Gibbons et al. 2000; Thomas et al. 2004; Todd et al. 2010; Urban 2015). In particular, accurate species distribution is a key for predicting dispersal possibilities and assessing the potential ecological impacts in the face of changing ecosystems (Fujisaki et al. 2014; Kraus 2015). Studies determining current and predicting potential future distributions, based on changing environmental conditions, are increasingly important for reptiles (Sinervo et al. 2010; Acheson and Kerr 2018; Sancholi 2018). Being ecototherms, reptiles are highly vulnerable to future climate change (Angilletta Jr. et al. 1999).

(C) The Author(s). 2020 Open Access This article is distributed under the terms of the Creative Commons Attribution 4.0 International License (http://creativecommons.org/licenses/by/4.0/), which permits unrestricted use, distribution, and reproduction in any medium, provided you give appropriate credit to the original author(s) and the source, provide a link to the Creative Commons license, and indicate if changes were made. The Creative Commons Public Domain Dedication waiver (http://creativecommons.org/publicdomain/zero/1.0/) applies to the data made available in this article, unless otherwise stated. 
Identification of suitable habitats, potential distribution range, and investigation of distribution changes have been studied using species distribution models (Guisan and Thuiller 2005; Ortega-Huerta and Peterson 2008), such as maximum entropy (MaxEnt), ensemble, and envelope (Guisan and Thuiller 2005; Norberg et al. 2019). Among them, the MaxEnt model reliably predicts suitable habitat using presence records and pseudo-absence points (Phillips et al. 2006, 2009; Elith et al. 2006). Reptile studies have used MaxEnt to estimate potential distributions (Rödder et al. 2008; Huang et al. 2011; Solhjouy-Fard et al. 2012), predict distribution changes due to climate change (Srinivasulu and Srinivasulu 2016; Ofori et al. 2017; Berriozabal-Islas et al. 2018), and evaluate range expansions of introduced species (Buckland et al. 2014; Fujisaki et al. 2014; Weterings and Vetter 2018).

Schlegel's Japanese gecko (Gekko japonicus), a small, nocturnal gecko, was first described based on specimens collected from Japan (Duméril and Bibron 1836), followed by those from Chusan Island, Zhejiang Province, China (Cantor 1842) and Busan, Korea (Stejneger 1907). In Japan, G. japonicus broadly occurs on the main islands (exclusive of high altitude and latitude areas) and some peripheral islets (Wada 2003). The current distribution of G. japonicus in China includes the eastern coast extending westward to eastern Sichuan and northward to southern Shaanxi and Gansu Provinces (Zhao and Adler 1993). In Korea, populations are only found in southern coastal cities such as Busan, Changwon, and Mokpo (Lee et al. 2004; Kim et al. 2017). Only few basic ecological and genetic studies have been done on G. japonicus (Toda et al. 2003; Zhang et al. 2009; Kim et al. 2018, 2019; Park et al. 2019). Recent concerns regarding area of origin and gentic relationships among populations are growing due to range expansions of G. japonicus in Korea and Japan, possibly due to anthropogenic factors or climate change (Toda et al. 2003; Kim et al. 2017). Without clarifying its distributional range, it is difficult to interpret the morphological and genetic divergence patterns in a geographic context (Kim 2019a; b). Although G. japonicus is distributed widely in Northeast Asia and artificial introductions have been suggested in Korea and Japan (Lee et al. 2004; Toda and Yoshida 2005), its distribution range is not fully resolved.

In this study, we use the MaxEnt species distribution model to predict the present distribution of G. japonicus across China, Japan, and Korea, as well as future changes following two climate change scenarios. These results contribute to future ecological studies of G. japonicus across its distributional range.

\section{Materials and methods}

\section{Collecting species location data for modeling}

We compiled location coordinate data of G. japonicus through literature review and fieldwork across China, Japan, and Korea (Table 1). For the literature review, we examined all reliable data from peer-reviewed papers and officially published booklets. For data from China, only a few locations $(<30)$ had coordinate data. To fill in this data gap, two researchers (Y.Z. and S.L.) with more than 20-year experience with G. japonicus in China, determined coordinates using the verbatim locality and Google Maps. For Japan, the distributional data is based on interviews with local residents and researchers (Wada 2003) and evaluated by H.O., who has more than 30-year experience with the species. In Korea, data was compiled from previous literature (Lee et al. 2004; Son et al., 2008; Kim et al. 2017), and only used for locations that we could confirm directly. In the Global Biodiversity Information Facility database (GBIF, https://www.gbif.org/), we found 37 locations of G. japonicus (10 in China, 22 in Japan, and 5 in Korea), all of which overlapped with our collected data. We conducted field surveys from August 2015 to October 2018 in regions of China (Wenzhou, Yancheng), Japan (Fukuoka, Tsushima and Innoshima Islands, Kobe, and Kyoto), and Korea (Busan, Changwon, Masan, Geoje, Mokpo, Ulsan, and Jeju) to confirm and gather new location data.

Table 1 Location and number of the occurrence points of Gekko japonicus obtained across China, Japan, and Korea and used for the modeling

\begin{tabular}{|c|c|c|}
\hline Country & District (no. of included cities) & No. of occurrence points \\
\hline \multirow[t]{13}{*}{ China } & Guangxi (3) & 3 \\
\hline & Guizhou (5) & 7 \\
\hline & Shaanxi (3) & 6 \\
\hline & Shanghai (1) & 3 \\
\hline & Anhui (7) & 15 \\
\hline & Jangxi (7) & 18 \\
\hline & Jiangsu (8) & 13 \\
\hline & Zhejiang (7) & 15 \\
\hline & Chongqing (1) & 10 \\
\hline & Fujian (5) & 7 \\
\hline & Henan (2) & 2 \\
\hline & Hunan (5) & 8 \\
\hline & Hubei (8) & 18 \\
\hline \multirow[t]{6}{*}{ Japan } & Kyushu (9) & 41 \\
\hline & Kansai (7) & 103 \\
\hline & Chugoku (6) & 27 \\
\hline & Kanto (2) & 39 \\
\hline & Shikoku (4) & 48 \\
\hline & Chubu (7) & 33 \\
\hline \multirow[t]{3}{*}{ Korea } & Busan (1) & 12 \\
\hline & Kyeongnam (2) & 3 \\
\hline & Cheonnam (1) & 1 \\
\hline Total & $22(101)$ & 432 \\
\hline
\end{tabular}


Our species distribution models included most regions in China, Japan, and Korea, and encompassed the entire known distribution range of G. japonicus (Zhou et al. 1982; Zhao and Adler 1993; Wada 2003; Lee et al. 2004). We excluded areas from our distribution models where it is known that G. japonicus is absent: Taiwan (Zhao and Adler 1993) and the Ryukyu Islands in Japan (H. O., Pers. Comm.). To avoid possible model biases due to the different amount of data collected among the modeling regions (Phillips et al. 2009; Fourcade et al. 2014), we selected each one coordinate from a $9-\mathrm{km}^{2}$ square, based on territory size (Park et al. 2019), using the Google random number generator (Google Inc., CA, USA). Finally, we used 432 total data points (125 in China, 291 in Japan, and 16 in Korea; Fig. 1, Additional file 1: Table S1) in our model (Table 1).

\section{Climate and environmental variables for modeling}

A 30 arc-seconds (c.a. $1 \mathrm{~km}$ ) unit grid size was used for extracting and modeling data. We used a total of 24 variables in the modeling: 19 climate variables (Bio 1-Bio 19) provided by WorldClim (ver. 1.4, Additional file 1 : Table S1) and five environmental variables (see below). Since there were many significant correlations between the extracted climate variables (Pearson's $r>0.101, p<$ 0.05 , of 128 out of 171 correlation cases), we conducted a principal component analysis (PCA) on the 19 climate variables using the rasterPCA function in the Rstoolbox (Leutner and Horning 2017), performed in R (ver. 3.4.0; $\mathrm{R}$ Core Team 2018). The first two principle components (PCA1 and PCA2) accounted for 99\% cumulative variation of the climate data (Additional file 1: Table S1), so we used these two PCAs in our modeling. The most highly correlated variable to PCA1 was temperature seasonality (Bio 4) and for PCA2 was annual precipitation (Bio 12). To predict the future potential distribution following climate change (Samy et al. 2016), we applied the same PCA analysis rate to the future climate variables. The present climate variables were derived from the past 30-year climate data (1960-1990) and the future climate variables were predicted over the 30-years of 2061-2080, provided by WorldClim (ver. 1.4). As future climate scenarios, we used the Representative Concentration Pathways (RCP 4.5 and RCP 8.5), which adopted the Hadley Center Global Environmental Model ver.2 Earth System (HadGEM2-ES), for predicting future suitable habitat distribution in 2070 (Collins et al. 2011; IPCC 2013).

The five environmental variables used in the model were selected based on previous studies and our expert knowledge from field survey of G. japonicus: altitude, slope, land cover type, Normalized Difference Vegetation Index (NDVI), and distance to the nearest urban and built-up area (Fattahi et al. 2014; Zhang et al. 2014; Acheson and Kerr 2018; Kim et al. 2018; Ribeiro et al. 2018). The altitude and slope for each location were extracted from the WorldClim database (ver. 1.4), and the land cover type and distance to the nearest urban and builtup area were extracted from MODIS Land Cover Type Product (MCD12Q1) (source: Global Land Cover Facility, http://glcf.umd.edu/data/lc/, Additional file 1: Table S2). NDVI was obtained from the United States Geological Survey (USGS; https://landcover.usgs.gov/green veg.php). The distance to the nearest urban and built-up area was calculated as the distance between the center of

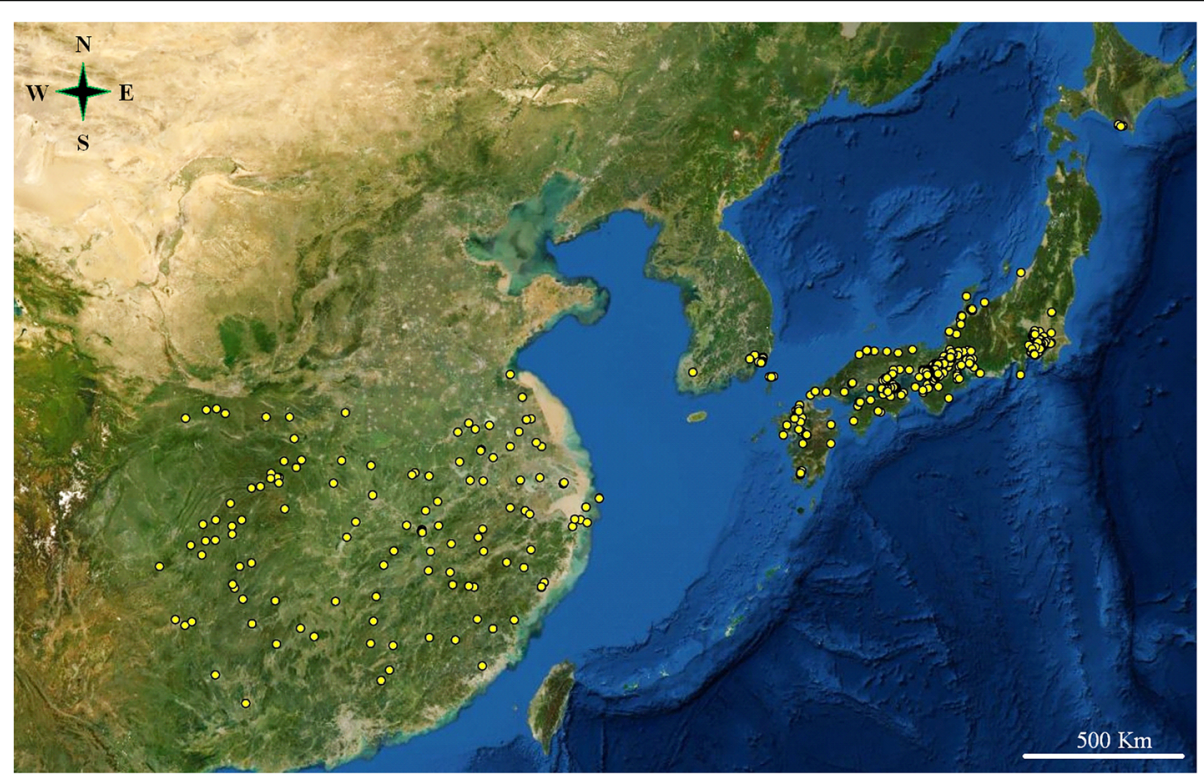

Fig. 1 Presence records of Gekko japonicus in China, Japan, and Korea, which were used in the MaxEnt species distribution modeling 
the presence-grid square and the boundary of the nearest urban and built-up area using the Euclidean distance tool in ArcGIS (ver. 10.1 ESRI Inc., Redlands, USA). When the center of a presence-grid square was within urban and built-up area, the distance was considered 0 $\mathrm{km}$. The current-state values of the five environmental variables were used for both the present and future distribution models. Overall, climate and environmental variable data for 432 occurrence points, were obtained at present and future (2070) timeframes and used in our modeling design (Additional file 1: Table S3).

\section{Conducting present and future species distribution modeling}

We conducted the species distribution modeling for suitable habitats of G. japonicus using MaxEnt software (ver. 3.3.3 K) (Phillips et al. 2009). A randomly selected $75 \%$ of the presence records were used as training data, while the remaining 25\% were used as testing data for model validation (Cianfrani et al. 2010; Berriozabal-Islas et al. 2018). Modeling was replicated 15 times using a bootstrap method, with each replicate having 5000 iterations. The fitness of the model was evaluated by using area under the curve (AUC), which is the area under the receiver operating characteristics (ROC) curve (Jiménez-Valverde 2012). For AUC (range, 0.1-1), the model is more reliable when the value is closer to 1.0. The contribution of the environmental variables to the model was evaluated by the permutation importance of each variable, considering that there were many significant correlations between the variables used in the modeling (Pearson's $r>0.138, p<$ $0.05,11$ out of total 15 comparison cases; Fattahi et al. 2014). The independent contribution of each environmental variable to the model was assessed using a Jackknife test for the AUC (Jiménez-Valverde 2012). We set the major suitable habitats to be more than 0.55 probability of presence in the model (Liu et al. 2005; Phillips et al. 2009), taking the average predicted probability of species-presence of the presence records as the 0.55 threshold. The average probability/suitability approach was known as an effective threshold-determining approach (Liu et al. 2005).

In the analysis of the future potential distribution according to the climate change scenarios, we evaluated the effects of climate change on the distribution of G. japonicus, analyzing the changes in the major suitable habitat areas between current and future (2070) timeframes.

\section{Results}

\section{The present distribution of suitable habitat}

The AUC value of the model was 0.936. Major suitable habitats were found in 62,297 out of evaluated 4,491,379$\mathrm{km}^{2}$ grid squares (1.4\%). By country, Japan had 69.3\% (43, $176 \mathrm{~km}^{2}$ ) of the major suitable habitats, followed by China with $27.1 \%\left(16,895 \mathrm{~km}^{2}\right)$, and Korea with $4.2 \%\left(2624 \mathrm{~km}^{2}\right)$.
Most major suitable habitats were located in urban areas such as coastal (Shanghai and Ningbo) and inland cities (Chongqing, Yingtan, and Quzhou) in China; western, southern, and northern coastal cities (Fukuoka, Osaka, Nagoya, and Kyoto) of Kyushu and Honshu in Japan; and at southeastern coastal cities (Busan and Changwon) in Korea (Fig. 2a, b). In the non-urban areas, major suitable habitats were sporadically found in the mid-western inlands of China and suburban areas of Japan. Also, suitable habitats were predicted where G. japonicus is previously unrecorded, in Qingdao, China, and Jeju Island and southeastern cities (Pohang and Ulsan) in Korea (Figs. 1 and 2a, b).

We list the major environmental variables in order of permutation importance: climate PCA1 (66.5\%), altitude (13.0\%), distance from the urban and built-up area (9.3\%), slope (4.3\%), climate PCA2 (4.2\%), NDVI (1.4\%), and land cover type (1.4\%). In the response curves of the variables, greater habitat suitability was predicted at middle values of climate PCA1, climate PCA2, and NDVI, while that was at lower of altitude and higher of slope (Additional file 1: Figure S1). In the Jackknife tests, when each variable independently evaluated for its model contribution, the two variables with the greatest contribution were distance to nearest urban and built-up area and climate PCA1. When each variable was independently evaluated through the omitting process, climate PCA1 had the greatest effect on the distribution model (Additional file 1: Figure S2).

\section{Future distribution according to climate change}

In 2070 based on RCP 4.5, suitable habitats will decrease by $18.4 \%\left(11,463 \mathrm{~km}^{2}\right)$ compared to the present habitats (Fig. 2a-d). For individual countries, habitats will decrease by $19.8 \%\left(3545 \mathrm{~km}^{2}\right)$ in China, $16.3 \%\left(7038 \mathrm{~km}^{2}\right)$ in Japan, and $12.5 \%\left(328 \mathrm{~km}^{2}\right)$ in Korea. In China, suitable habitats are expected to decrease in and around Shanghai and Huangshan Mountain, but increase in coastal (Taizhou) and inland (Chongqing, Yichang, Suzhou, and Quzhou) cities. In Japan, a decrease of suitable habitats are predicted in northern coastal cities of Honshu (Niigata, Kanazawa, and Toyama) and southern areas (Kyushu and Shikoku), and eastern coastal cities (Nagoya and Fukushima). In Korea, decrease is predicted in a coastal city (Ulsan) (Fig. 2c, d).

In 2070, based on RCP 8.5, suitable habitats are predicted to decrease by $10.4 \%\left(6479 \mathrm{~km}^{2}\right)$ compared to the present habitats (Fig. 2a, b, e, f). In China and Japan, the habitats are predicted to decrease by $5.5 \%\left(929 \mathrm{~km}^{2}\right)$ and $14.8 \%\left(6390 \mathrm{~km}^{2}\right)$, respectively, while in Korea, increase by $22.3 \%\left(585 \mathrm{~km}^{2}\right)$. Decrease of the suitable habitats in China is greater in Shanghai and Huangshan Mountain areas, while increases of the habitats are more evident in inland cities such as Chongqing and Quzhou and eastern coastal cities such as Ningbo and Taizhou. In Japan, some increase is predicted in Fukuoka, but even greater 


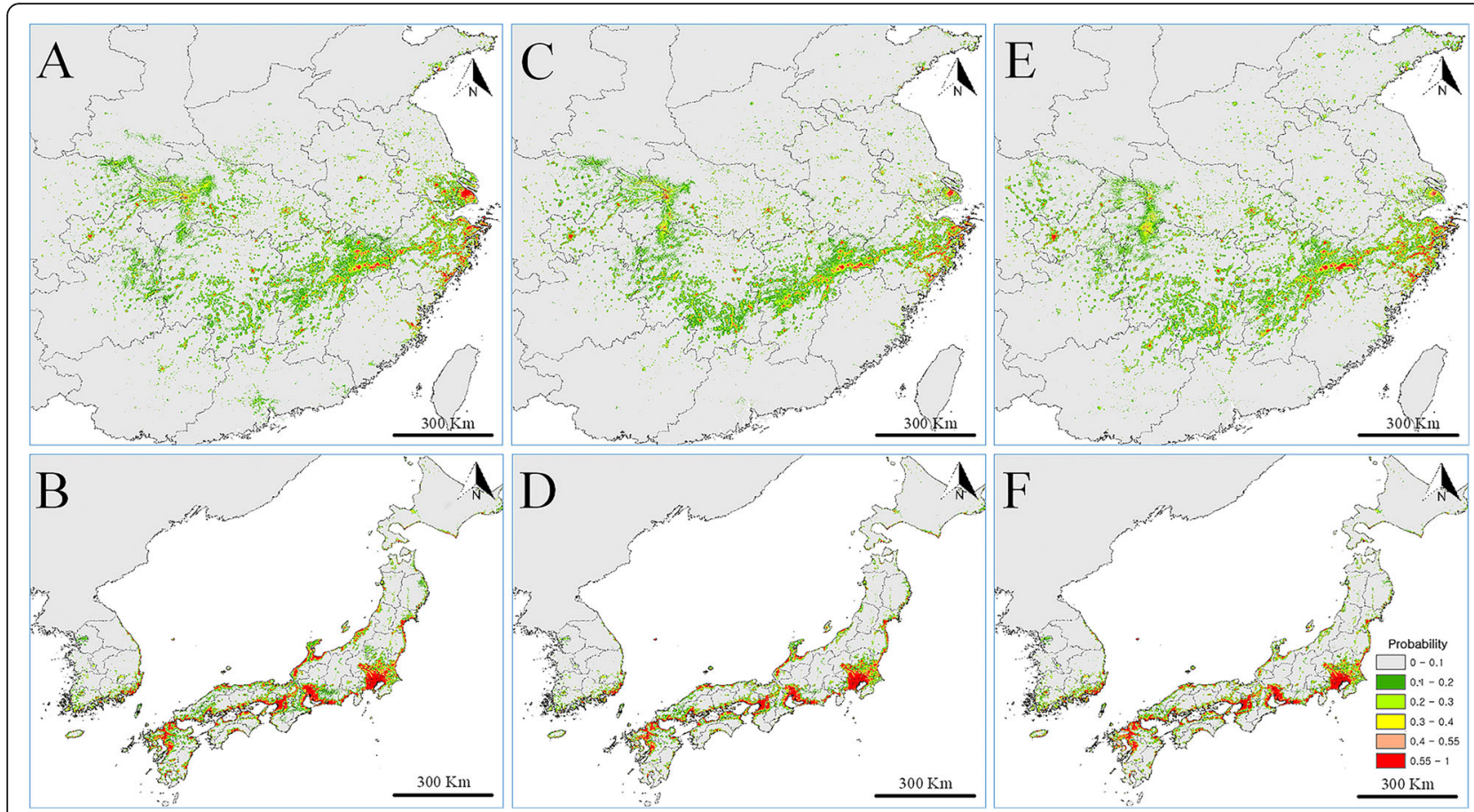

Fig. 2 a, b Present (1960 1990) and c-f future (2016-2080) distribution of the suitable habitats of Gekko japonicus over its entire distribution range according to climate change scenarios of RCP 4.5 (c, $\mathbf{d})$ and $8.5(\mathbf{e}, \mathbf{f})$, which predicted from the MaxEnt species distribution modeling

decreases are expected in northern coastal cities of Honshu and in Fukushima and Tokyo. Unlike China and Japan, suitable habitats in Korea are predicted to increase in major coastal (Busan, Changwon, and Kimhae) and inland cities (Gwangju and Daegu) (Fig. 2e, f).

\section{Discussion}

In this study, we predicted the current and future distributions of G. japonicus. Current predictions identified suitable habitats in large or mid-size cities along the eastern coast and inland areas of China; western, southern, and northern coastal cities of Honshu and Kyushu in Japan; and in southern coastal cities of Korea. More than $69 \%$ of current suitable habitats were found in Japan. Temperature seasonality (climate PCA1), altitude, and the distance to the nearest urban and built-up area were major determinants of the distribution. Following climate change, decreases of suitable habitats are predicted to occur in some major coastal habitats of China and Japan, but partial increases are also expected in inland areas of China and southern parts of Korea.

The distribution of suitable habitats of G. japonicus can be described as coastal cities and isolated non-urban areas, regardless of country. These results show that G. japonicus is well adapted to urban ecosystems, where favorable environments are available, such as a variety of shelters, low predation rates, and abundant food supplies (McKinney 2002; Parris 2016; Kim et al. 2018, 2019). Gekko japonicus seems to fit the concept of a synurbic species or urban dweller-when the distributional range is wider and the population density is greater in a city compared to natural areas (Francis and Chadwick 2011; Fischer et al. 2015). Although it is not known how many populations are still present in natural areas and the level of genetic diversity in urban populations, urban cities seem to be important habitats for G. japonicus. Studies on the basic ecology and genetic diversity of G. japonicus in isolated, non-urban areas (e.g., inland areas of China and suburban areas in Japan) are needed because these populations might represent pre-urban, wild populations of the species (Wada 2003). Furthermore, presence of G. japonicus populations in Qingdao city in China, where commercial trade is active among China, Japan, and Korea (Mitsuhashi et al. 2005), may represent potential anthropogenic dispersal routes of the species among the countries.

In the modeling, key environmental variables determining distributions of suitable habitats included climate PCA1 (mostly represented by temperature seasonality; annual standard deviation in temperature), altitude, and the distance to the nearest urban and built-up area. In nocturnal ectothermic species, appropriate temperature conditions guarantee nocturnal activity and winter hibernation and is crucial for their distribution (Angilleta jr et al. 1999; Park et al. 2019). Similarly, climate PCA1 explained more than $66 \%$ of the suitable habitat distribution of nocturnal G. japonicus. Previous studies observed 
that low winter temperature reduced the survivorship of introduced Burmese pythons (Python bivittatus) in Florida (Mazzotti et al. 2011), and limited expansion of introduced many-lined sun skinks (Eutropis multifasciata) to lower altitudes in Taiwan (Lin et al. 2019). Second, the importance of low altitude seems to be related to the nocturnal lifestyle and interspecific competition of $G$. japonicus. G. japonicus seems to prefer lowlands where night temperature are higher relative to the highlands. In a recent radio-tracking study, G. japonicus used only lowland areas as habitats (Park et al. 2019), although both lowland and highland forests were available. Interspecific competition between G. tawaensis and G. japonicus may also restrict the species to lowland areas (Toda et al. 2003). Third, the importance of the distance to the nearest urban and built-up area might reflect favorable urban environmental conditions for G. japonicus, such as abundant refuges, food, and mild temperatures (McKinney 2002; Parris 2016). In other words, a combination of favorable elements in urban environments likely contributes to G. japonicus flourishing in cities. In general, when considering that climate change affects cities greater than natural habitats (McCarthy et al. 2010), suitable habitats located in urban areas are highly vulnerable to future climate change.

Although a partial increase in suitable habitats is predicted in some parts of Korea and China, an overall decrease is expected across G. japonicus range due to climate change. Effects of climate change on the distribution of lizards are somewhat controversial, having both positive and negative effects depending on species (Huey and Tewksbury 2009; Sinervo et al. 2010; Bonino et al. 2015; Weterings and Vetter 2018). Three major patterns are predicted due to climate change in our modeling. First, suitable habitat is expected to almost disappear (RCP 8.5; 2070 projections) at the frontier zone of climate change: coastal areas of China (Shanghai and neighboring areas) and northern coastal areas of Honshu, Japan (Kanazawa, Niigata, and Toyama). Losing these major habitats would likely cause population size to decrease in these areas. Such large climatic effects at the front distribution-range edge of the climate change zone are predicted in other reptile species (Sinervo et al. 2010; Rehm et al. 2015). Second, the size of suitable habitats in large cities will decrease. These reductions are evident in Shanghai, Nagoya, Fukushima, and Tokyo. Considering that climate change generally impacts cities more severely than natural areas (McCarthy et al. 2010), our results suggest that if the appropriate habitat is not maintained or provided for G. japonicus, the population size of G. japonicus in urban areas will greatly decrease in the future due to climate change. Third, some increases in suitable habitats are predicted in China (Chongqing, Yingtan, and Quzhou) and Korea (Busan, Ulsan, Daegu, and Gwangju). Unfortunately, such increases are relatively small and will not compensate for the decreases of suitable habitats in other regions (see above) (Fig. 1). This result also shows that, depending on the region, climatic changes can cause the partial expansion of suitable habitat area (Parmesan 2006; Bonino et al. 2015) and these regions might function as potential refuges for preservation of the species under rapidly changing climate.

\section{Conclusions}

In conclusion, we predicted the present and future distributions of G. japonicus. Predicted suitable habitats for the present are located in coastal cities of Japan, China, and Korea, as well as isolated patches of inland China. Important variables influencing distribution were temperature seasonality, altitude, and the distance to the nearest urban and built-up area, which might be related to lowland, coastal environmental conditions. Following predicted scenarios of climate change, suitable habitat is expected to shrink along coastlines, particularly at the coastal-edge of climate change zone. Overall, our results provide essential distribution range information for future ecological studies of G. japonicus across its distribution range.

\section{Supplementary information}

Supplementary information accompanies this paper at https://doi.org/10 1186/s41610-020-0147-y.

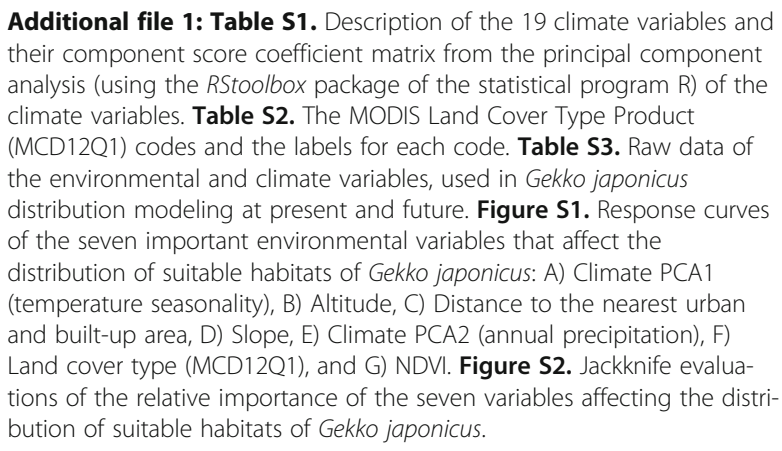

\section{Abbreviations \\ AUC: Area under the curve; MaxEnt: Maximum entropy; MCD12Q1: MODIS Land Cover Type Product; MODIS: Moderate resolution imaging spectroradiometer; NDVI: Normalized Difference Vegetation Index; PCA: Principal component analysis; RCP: Representative Concentration Pathway; ROC: Receiver operating characteristics}

\section{Acknowledgments}

We thank Drs. Jong-Nam Lee, II-Hun Kim, and Woo-Jin Choi and Hwan-Jin Jang for their help in field surveys and Alejandro Grajal-Puche for helpful comments on English usage and contents.

\section{Authors' contribution}

DIK, IKP, SYB, and DP designed the study, performed the analysis, and wrote the manuscript. YPZ, SRL, and JSK gathered the data and reviewed the manuscript. JJF and $\mathrm{HO}$ conceived the study and reviewed the manuscript. DIK and IKP made equal contributions to this study. All authors read and approved the final manuscript. 


\section{Funding}

This research was supported by the Basic Science Research Program through the National Research Foundation of Korea (NRF) funded by the Ministry of Education (no. 2016R1D1A1B03931085) to D Park and Natural Sciences Foundation of China (no. 31971419) to YP Zhang.

\section{Availability of data and materials}

The datasets generated during and/or analyzed during the current study are available from supplementary tables.

\section{Ethics approval and consent to participate}

This research was conducted within the guidelines and approval of the Institutional Animal Care and Use Committee of Kangwon National University (KW-161128-2).

\section{Consent for publication}

Not applicable

\section{Competing interests}

The authors declare that they have no competing interests.

\section{Author details}

'Department of Biology, Kangwon National University, ChuncheonKangwon, 24341, Republic of Korea. ${ }^{2}$ Department of Animal Ecology and Tropical Biology (Zoology III) Biocenter, University of Würzburg, 97074 Würzburg, Germany. ${ }^{3}$ Science Unit, Lingnan University, Tuen Mun, New Territories, Hong Kong, China. ${ }^{4}$ College of Life and Environmental Sciences, Wenzhou University, Wenzhou, 325035 Zhejiang, People's Republic of China. Institute of Natural and Environmental Sciences, University of Hyogo, Yayoigaoka 6, Sanda, Hyogo 669-1546, Japan. ${ }^{6}$ Division of Science Education, Kangwon National University, ChuncheonKangwon, 24341, Republic of Korea.

\section{Received: 7 October 2019 Accepted: 7 January 2020}

\section{Published online: 28 January 2020}

\section{References}

Acheson ES, Kerr JT. Nets versus spraying: a spatial modelling approach reveals indoor residual spraying targets Anopheles mosquito habitats better than mosquito nets in Tanzania. PLoS One. 2018;13(10):e0205270.

Angilletta MJ Jr, Montgomery LG, Werner YL. Temperature preference in geckos: diel variation in juveniles and adults. Herpetologica. 1999;55:212-22.

Berriozabal-Islas C, Rodrigues JFM, Ramirez-Bautista A, Becerra-López JL, NietoMontes de Oca A. Effect of climate change in lizards of the genus Xenosaurus (Xenosauridae) based on projected changes in climatic suitability and climatic niche conservation. Ecol Evol. 2018;8:6860-71.

Bonino MF, Moreno Azócar DL, Schulte JA II, Cruz FB. Climate change and lizards: changing species' geographic ranges in Patagonia. Reg Environ Chang. 2015; 15:1121-32.

Buckland S, Cole NC, Aguirre-Gutiérrez J, Gallagher LE, Henshaw SM, Besnard A, Tucker RM, Bachraz V, Ruhomaun K, Harris S. Ecological effects of the invasive giant Madagascar day gecko on endemic Mauritian geckos: applications of binomial-mixture and species distribution models. PLoS One. 2014;9(4): e88798.

Cantor T. General features of Chusan, with remarks on the flora and fauna of that island. Ann Mag Nat Hist London. 1842;9:486-9.

Cianfrani C, Lay GL, Hirzel AH, Loy A. Do habitat suitability models reliably predict the recovery areas of threatened species? J Appl Ecol. 2010;47:421-30.

Collins WJ, Bellouin N, Doutriaux-Boucher M, Gedney N, Halloran P, Hinton T, Hughes J, Jones CD, Joshi M, Liddicoat S, Martin G, O'Connor F, Rae J, Senior C, Sitch S, Totterdell I, Wiltshire A, Woodward S. Development and evaluation of an earth-system model - HadGEM2. Geosci Model Dev. 2011;4:997-1062.

Duméril AMC, Bibron G. Erpétologie Générale ou Histoire Naturelle Complète des Reptiles, vol. 3. Paris: Librairie Encyclopédique Roret; 1836.

Elith J, Graham CH, Anderson RP, Dudík M, Ferrier S, Guisan A, Hijmans RJ, Huettmann F, Leathwick JR, Lehmann A, Li J, Lohmann LG, Loiselle BA, Manion G, Moritz C, Nakamura M, Nakazawa Y, Overton JM, Peterson AT, Phillips SJ, Richardson K, Scachetti-Pereira R, Schapire RE, Soberón J, Williams $\mathrm{S}$, Wisz MS, Zimmermann NE. Novel methods improve prediction of species' distributions from occurrence data. Ecography. 2006;29:129-51.

Fattahi R, Ficetola GF, Rastegar-Pouyani N, Avci A, Kumlutas Y, llgaz C, Yousefkhani SSH. Modeling the potential distribution of the Bridled skink,
Trachylepis vittata (Olivier, 1804), in the Middle East. Zool Middle East. 2014; 60:208-16.

Fischer JD, Schneider SC, Ahlers AA, Miller JR. Categorizing wildlife responses to urbanization and conservation implications of terminology. Conserv Biol. 2015;29:1246-8.

Fourcade Y, Engler JO, Rödder D, Secondi J. Mapping species distributions with MaxEnt using a geographically biased sample of presence data: a performance assessment of methods for correcting sampling bias. PLoS One. 2014;9(5):e97122

Francis RA, Chadwick MA. What makes a species synurbic? Appl Geogr. 2011;32: $514-21$.

Franklin J. Mapping species distributions: spatial inference and prediction. Cambridge: Cambridge University Press; 2009.

Fujisaki I, Mazzotti FJ, Watling J, Krysko KL, Escribano Y. Geographic risk assessment reveals spatial variation in invasion potential of exotic reptiles in an invasive species hotspot. Herpetol Conserv Biol. 2014;10:621-32.

Gibbons JW, Scott DE, Ryan TJ, Buhlmann KA, Tuberville TD, Metts BS, Greene JL, Mills T, Leiden Y, Poppy S, Winne CT. The global decline of reptiles. Déjà Vu amphibians BioScience. 2000;50:653-66.

Guisan A, Thuiller W. Predicting species distribution: offering more than simple habitat models. Ecol Lett. 2005:8:993-1009.

Huang Y, Dai Q, Chen Y, Wan H, Li J, Wang Y. Lizard species richness patterns in China and its environmental associations. Biodivers Conserv. 2011;20:1399414.

Huey RB, Tewksbury JJ. Can behavior douse the fire of climate warming? PNAS. 2009;106:3647-8

IPCC. Climate change 2013: the physical science basis. Contribution of Working Group I to the Fifth Assessment Report of the Intergovernmental Panel on Climate Change. Cambridge: Cambridge University Press; 2013.

Jiménez-Valverde A. Insights into the area under the receiver operating characteristic curve (AUC) as a discrimination measure in species distribution modeling. Glob Ecol Biogeogr. 2012;21:498-507.

Kim DI. Species distribution modeling, microhabitat use, and morphological variation of the Schlegel's Japanese gecko (Gekko japonicus). Doctoral Dissertation, Kangwon National University; 2019b.

Kim DI, Choi WJ, Park IK, Kim JS, Kim IH, Park D. Comparisons of microhabitat use of Schlegel's Japanese gecko (Gekko japonicus) among three populations and four land cover types. J Ecol Environ. 2018;42(11):198-204.

Kim DI, Park IK, Kim JS, Ota H, Choi WJ, Kim IH, Park D. Spring and summer microhabitat use by Schlegel's Japanese gecko, Gekko japonicus (Reptilia: Squamata: Gekkonidae), in urban areas. Anim Cells Syst. 2019;23:64-70.

Kim HT, Bae YH, Kim H, Kim D, Borzée A. Gekko japonicus (Schlegel's Japanese gecko). Herpetol Rev. 2017;48:588.

Kim JS. Analysis of genetic diversity and relationship of the Schlegel's Japanese gecko (Gekko japonicus). MS Thesis, Kangwon National University; 2019a.

Kraus F. Impacts from invasive reptiles and amphibians. Annu Rev Ecol Evol Syst. 2015:46:75-97.

Lee JN, Kang SG, Lee IS. The study on the Gekko japonicus in Korea. Bull Basic Sci Res Inst Kyeongsung Univ. 2004;16:57-63.

Leutner B, Horning N. RStoolbox: tools for remote sensing data analysis. R package version 0.1.9. https://CRAN.R-project.org/package=RStoolbox; 2017.

Lin TE, Chen TY, Wei HL, Richard R, Huang SP. Low cold tolerance of the invasive lizard Eutropis multifasciata constrains its potential elevation distribution in Taiwan. J Therm Biol. 2019;82:115-22.

Liu C, Berry PM, Dawson TP, Pearson RG. Selecting thresholds of occurrence in the prediction of species distributions. Ecography. 2005;28:385-93.

Mazzotti FJ, Cherkiss MS, Hart KM, Snow RW, Rochford MR, Dorcas ME, Reed RN. Cold-induced mortality of invasive Burmese pythons in South Florida. Biol Invasions. 2011;13:143-51.

McCarthy MP, Best MJ, Betts RA. Climate change in cities due to global warming and urban effects. Geophys Res Lett. 2010;37:L09705.

McKinney ML. Urbanization, biodiversity, and conservation: the impacts of urbanization on native species are poorly studied, but educating a highly urbanized human population about these impacts can greatly improve species conservation in all ecosystems. BioScience. 2002;52:883-90.

Mitsuhashi I, Sasa K, Li Z, Gao H, Kim HS. Future development of sea transportation corridors in Northeast Asia. Proc East Asia Soc Transp Stud. 2005;5:1687-702.

Norberg A, Abrego N, Blanchet FG, Adler FR, Anderson BJ, Anttila J, Araújo MB, Dallas T, Dunson D, Elith J, Foster SD, Fox R, Franklin J, Godsoe W, Guisan A, O'Hara B, Hill NA, Holt RD, FKC H, Husby M, Kålås JA, Lehikoinen A, Luoto M, 
Mod HK, Newell G, Renner I, Roslin T, Soininen J, Thuiller W, Vanhatalo J, Warton D, White M, Zimmermann NE, Gravel D, Ovaskainen O. A comprehensive evaluation of predictive performance of 33 species distribution models at species and community levels. Ecol Monog. 2019; 89(3): 01370

Ofori BY, Stow AJ, Baumgartner JB, Beaumont LJ. Combining dispersal, landscape connectivity and habitat suitability to assess climate-induced changes in the distribution of Cunningham's skink, Egernia cunninghami. PLoS One. 2017; 12(9):e0184193.

Ortega-Huerta MA, Peterson AT. Modeling ecological niches and predicting geographic distributions: a test of six presence-only methods. Rev Mex Biodivers. 2008;79:205-16.

Park IK, Kim DI, Fong JJ, Park D. Home range size and overlap of the small nocturnal Schlegel's Japanese gecko (Gekko japonicus), introduced into a suburban city park. Asian Hereptol Res. 2019;10(4):261-9.

Parmesan C. Ecological and evolutionary responses to recent climate change. Annu Rev Ecol Syst. 2006:37:637-69.

Parris KM. Ecology of urban environments. West Susses: Wiley; 2016.

Phillips SJ, Anderson RP, Schapire RE. Maximum entropy modelling of species geographic distributions. Ecol Model. 2006;190:231-59.

Phillips SJ, Dudík M, Elith J, Graham CH, Lehmann A, Leathwick J, Ferrier S. Simple selection bias and presence-only distribution models: implications for background and pseudo-absence data. Ecol Appl. 2009;19:181-97.

R Core Team. R: a language and environment for statistical computing. Vienna: URL https://www.R-project.org/: R Foundation for Statistical Computing; 2018.

Rehm EM, Olivas P, Stroud J, Feeley KJ. Losing your edge: climate change and the conservation value of range-edge populations. Ecol Evol. 2015;5:4315-26.

Ribeiro LB, Gomides SC, Ferreira JVA, Magalhães AJC Jr. Modeling the potential geographic distribution of the poorly known neotropical lizard Anotosaura vanzolinia Dixon, 1974 (Squamata, Gymnophthalmidae) in Northeast Brazil. Turkish J Zool. 2018;42:732-8.

Rödder D, Solé M, Böhme W. Predicting the potential distributions of two alien invasive Housegeckos (Gekkonidae: Hemidactylus frenatus, Hemidactylus mabouia). North-West J Zool. 2008;4:236-46.

Samy AM, Elaagip AH, Kenawy MA, Ayres CFJ, Peterson AT, Soliman DE. Climate change influences on the global potential distribution of the mosquito Culex quinquefasciatus, vector of West Nile virus and lymphatic filariasis. PLoS One. 2016;11(10):e0163863.

Sancholi N. Effects of climate change on Paralaudakia lehmanni (Nicolsky, 1896) (Reptilia: Agamidae) in Central Asia. Contemp Prob Ecol. 2018;11(6):682-6.

Sinervo B, Méndez-de-la-Cruz F, Miles DB, Heulin B, Bastiaans E, Villagrán-Santa Cruz M, Lara-Resendiz R, Martínez-Méndez N, Calderón-Espinosa ML, MezaLázaro RN, Gadsden H, Avila LJ, Morando M, De la Riva IJ, Sepulveda RV, Rocha CFD, Ibargüengoytía N, Puntriano CA, Massot M, Lepetz V, Oksanen TA, Chapple DG, Bauer AM, Branch WR, Clobert J, Sites JW Jr. Erosion of lizard diversity by climate change and altered thermal niches. Science. 2010;328: 894-9.

Solhjouy-Fard S, Sarafrazi A, Moeini MM, Ahadiyat A. Predicting habitat distribution of five heteropteran pest species in Iran. J Insect Sci. 2012;13(1):116.

Son SB, Lee SC, Lee YW, Cho YK. Introduction of Schlegel's Japanese gecko (Gekko japonicus). Nature Ecol. 2008;13:10-29.

Srinivasulu A, Srinivasulu C. All that glitters is not gold: a projected distribution of the endemic Indian golden gecko Calodactylodes aureus (Reptilia: Squamata: Gekkonidae) indicates a major range shrinkage due to future climate change. JoTT. 2016;8(6):8883-92.

Stejneger L. Herpetology of Japan and adjacent territory (no. 58). Washington: Government Print Office; 1907.

Thomas CD, Cameron A, Green RE, Bakkenes M, Beaumont LJ, Collingham YC, Erasmus BFM, de Siqueira MF, Grainger A, Hannah L, Hughes L, Huntley B, van Jaarsveld AS, Midgley GF, Miles L, Ortega-Huerta MA, Peterson AT, Phillips OL, Williams SE. Extinction risk from climate change. Nature. 2004;427: $145-8$.

Toda M, Hikida T, Okada S, Ota H. Contrasting patterns of genetic variation in the two sympatric geckos Gekko tawaensis and G. japonicas (Reptilia: Squamata) from western Japan, as revealed by allozyme analyses. Heredity. 2003;90:90-7.

Toda M, Yoshida T. Issues and perspectives regarding invasive alien species of amphibians and reptiles in Japan. Bull Herpetol Soc Jpn. 2005;2005:139-49.

Todd BD, Willson JD, Gibbons JW. The global status of reptiles and causes of their decline. In: Sparling DW, Linder G, Bishop CA, Krest S, editors. Ecotoxicology of amphibians and reptiles. Boca Raton: CRC Press; 2010.
Urban MC. Accelerating extinction risk from climate change. Science. 2015;348:571-3.

Wada T. Distribution of house-dwelling geckos in Japan, based on a research using questionnaire. Shizenshi-Kenkyu. 2003;3(2):2-19 (in Japanese).

Weterings R, Vetter KC. Invasive house geckos (Hemidactylus spp.): their current, potential and future distribution. Curr Zool. 2018;64(5):559-73.

Zhang Y, Chen C, Li L, Zhao C, Chen W, Huang Y. Insights from ecological niche modeling on the taxonomic distinction and niche differentiation between the black-spotted and red-spotted tokay geckos (Gekko gecko). Ecol Evol. 2014:4:3383-94.

Zhang YP, Du WG, Zhu LJ. Differences in body size and female reproductive traits between two sympatric geckos, Gekko japonicus and Gekko hokouensis. Folia Zool. 2009;58:113-22.

Zhao EM, Adler K. Herpetology of China. Oxford: Society for the Study of Amphibians and Reptiles; 1993.

Zhou KY, Liu YZ, Li DJ. Three new species of Gekko and remarks on Gekko hokouensis (Lacertiformes, Gekkonidae). Acta Zootaxon Sin. 1982;7:438-46.

\section{Publisher's Note}

Springer Nature remains neutral with regard to jurisdictional claims in published maps and institutional affiliations.
Ready to submit your research? Choose BMC and benefit from:

- fast, convenient online submission

- thorough peer review by experienced researchers in your field

- rapid publication on acceptance

- support for research data, including large and complex data types

- gold Open Access which fosters wider collaboration and increased citations

- maximum visibility for your research: over $100 \mathrm{M}$ website views per year

At BMC, research is always in progress.

Learn more biomedcentral.com/submissions 